\title{
Using Threshold Analysis to Assess the Robustness of Public Health Intervention Recommendations from Network Meta-Analyses: Application to Poison Prevention in Households with Children Under Five
}

Molly Wells ( $\sim$ meww3@leicester.ac.uk)

University of Leicester

Sylwia Bujkiewicz

University of Leicester

Stephanie J Hubbard

University of Leicester

\section{Research Article}

Keywords: network meta-analysis, National institute for health and care excellence, Non-randomised controlled trial

Posted Date: January 3rd, 2022

DOI: https://doi.org/10.21203/rs.3.rs-1178008/v1

License: (c) (1) This work is licensed under a Creative Commons Attribution 4.0 International License. Read Full License 


\section{Abstract}

\section{Background}

In the appraisal of clinical interventions, complex evidence synthesis methods, such as network metaanalysis (NMA), are commonly used to investigate the effectiveness of multiple interventions in a single analysis. The results from a NMA can inform clinical guidelines directly or be used as inputs into a decisionanalytic model assessing the cost-effectiveness of the interventions. However, there is hesitancy in using complex evidence synthesis methods when evaluating public health interventions. This is due to significant heterogeneity across studies investigating such interventions and concerns about their quality.

Threshold analysis has been developed to help assess and quantify the robustness of recommendations made based on results obtained from NMAs to potential limitations of the data. Developed in the context of clinical guidelines, the method may prove useful also in the context of public health interventions. In this paper, we illustrate the use of the method in the study investigating the effectiveness of interventions aiming to increase the uptake of poison prevention behaviours in homes with children aged 0-5.

\section{Methods}

Random effects NMA was carried out to assess the effectiveness of several interventions for increasing the uptake of poison prevention behaviours, focusing on the safe storage of other household products outcome. Threshold analysis was then applied to the NMA to assess the robustness of the intervention recommendations made based on the NMA.

\section{Results}

15 studies assessing seven interventions were included in the NMA. The results of the NMA indicated that complex intervention, including Education, Free/low-cost equipment, Fitting equipment and Home safety inspection, was the most effective intervention at promoting poison prevention behaviours. However, the threshold analyses highlighted that this intervention recommendation was not robust.

\section{Conclusions}

In our case study, threshold analysis allowed us to demonstrate that the intervention recommendation for promoting poison prevention behaviours was not robust to changes in the evidence due to potential bias. Therefore, caution should be taken when considering such interventions in practice. We have illustrated the potential benefit of threshold analysis and, therefore, encourage the use of the method in practice as a sensitivity analysis for NMA of public health interventions.

\section{Background}

Evidence synthesis methods, including systematic reviews and meta-analysis, are used in evidence-based decision-making, for example, carried out as part of the technology appraisals of new health interventions. A range of meta-analytic methods are available for different data scenarios. Pairwise meta-analysis pools 
evidence from multiple studies that compare head-to-head two interventions, that are the same or similar across studies, to gain a pooled overall estimate of the relative treatment effect. However, issues with pairwise meta-analysis arise when more than two interventions need to be compared. Network metaanalysis (NMA) expands on the pairwise meta-analysis framework by allowing for the comparison of multiple interventions in a single analysis. The results from a NMA are often used to inform a decisionanalytic model assessing the cost-effectiveness of the interventions [1]. The effectiveness and costeffectiveness of interventions are vital components in policy decision-making and the development of guidelines, for example, by the National Institute for Health and Care Excellence (NICE).

Despite the known benefits of NMA, there is some hesitancy in using NMA methods in public health intervention appraisals. Public health interventions can be highly complex as they can consist of multiple and often overlapping components. It is common to see substantial between-studies heterogeneity due to, for example, different study designs, which is often listed as the reason for not using meta-analysis methods [2].

As well as substantial between-studies heterogeneity, there is often concern regarding the quality of the studies evaluating public health interventions. Due to the nature of public health outcomes and corresponding interventions, there tends to be a broader range of study types in contrast to individualfocused randomised controlled trials (RCTs) typically seen in clinical settings. Due to the nature of RCTs, particularly the randomisation and blinding, they are considered to be the least biased source of evidence compared to other study designs such as non-randomised controlled trials (NRCTs) and observational studies. The broad range of study designs in public health introduces issues with the validity of the results from these studies and increases the potential risk of bias. This is one of the reasons behind the hesitancy for using NMA methods in the public health setting.

In a recent study, Smith et al (2021) highlighted that there is increasing use of evidence synthesis methods in the appraisals of public health interventions by NICE. Thirty-one percent (14/45) of NICE public health intervention appraisals used a meta-analysis as part of the statistical analysis assessing the effectiveness of such interventions, which is an increase of $8 \%$ since 2012. However, only one of these appraisals conducted a NMA [2].

All studies included in a NMA should be assessed in terms of their quality and the potential risk of bias. If the studies included in the NMA have issues with their conduct and design, causing problems with their validity or their relevance, then there will be concerns regarding the reliability and validity of the NMA estimates and rankings. The Cochrane risk of bias tool can be used to assess the quality and potential risk of bias for individual studies [3]. This is typically used for RCTs where the studies are assessed on several aspects whereby possible bias could occur. Each aspect of the trial design that could introduce bias is then assigned a judgment based on how susceptible the study is to bias. These judgements are rated "high", "low", or "unclear" [4]. For network meta-analysis, the Grading of Recommendations Assessment, Development and Evaluation (GRADE), also formerly known as GRADE NMA, has been developed to assess the quality of evidence contributing to the intervention contrasts for every pair of interventions. The quality of evidence for each contrast in the network is rated as high, moderate, low, or very low across five areas: 
inconsistency, study limitations, indirectness, imprecision, publication bias. However, as networks become larger, loops of evidence become more complex leading to GRADE NMA becoming insufficient. Furthermore, whilst there are tools or methods that exist to assess the quality of evidence in NMA, these do not indicate or consider the impact any potential bias has on the intervention recommendations, which is less useful for decision-makers and guideline developers [5].

Threshold analysis, a method recently proposed by Phillippo et al [3], quantifies the sensitivity of effect estimates and decisions resulting from a NMA to any changes in the evidence. In this paper, we aim to illustrate that the application of threshold analysis in the public health setting can allow researchers and policy makers to assess and quantify the credibility of the results from NMAs in the presence of evidence that could be biased. We illustrate this using an example of NMA investigating the effectiveness of interventions to increase the uptake of poison prevention behaviours in homes with children under 5 .

\section{Methods}

\section{Network meta-analysis}

Network meta-analysis (NMA) allows for the comparison of multiple interventions in a single analysis to obtain the relative effectiveness of all interventions compared to each other. In NMA, the structure of the network is used to gain indirect estimates of effects between interventions that have not been compared directly. For example, by combining trials that have direct evidence comparing interventions $B$ versus $A$ and trials of $C$ versus $B$, we can estimate the indirect relative effect of interventions $C$ versus $A$. The use of indirect evidence is suitable provided that we can assume the consistency in the network, indicating that there is little difference between the direct evidence from trials (in this case, trials of C versus A, if they exist in the network) and indirect evidence obtained from the network. By combining the direct and indirect evidence, NMA allows for the estimation of relative intervention effects for all interventions in the network and enables ranking of the interventions according to the probability of an intervention being the best, thus identifying the most effective intervention [6]. The results from the NMA are often incorporated into a decision-analytic model to consider the cost-effectiveness of interventions. We conducted a NMA in WinBUGS 1.4.3 using a Bayesian approach which gave effect estimates as odds ratios with $95 \%$ credible intervals.

\section{Threshold analysis}

Threshold analysis identifies how sensitive the intervention recommendations from a NMA are to the level of imprecision in the effect estimates [3]. It derives multiple thresholds that represent changes in the effect estimates that lead to a change in the intervention decision. As a result, the method can identify the smallest possible changes in the data point, in both the positive and negative direction, that can lead to the change in the conclusion of which intervention is deemed most optimal. Once the smallest threshold is identified from the analysis in either direction, the method allows us to construct an invariant interval for each effect estimate. An invariant interval represents the interval in which the effect estimate can lie within without altering the intervention decision. If either the $95 \%$ confidence or credible interval for an effect estimate extends beyond the invariant interval, then we can deduce that the intervention recommendation is sensitive 
to the level of imprecision in the effect estimate. Whereas, if the $95 \%$ confidence or credible interval lies within the invariant interval, then this means that the intervention decision for that estimate is robust.

Threshold analysis can be conducted at the study level and the contrast level. Study level threshold analysis considers the impact of imprecision in individual studies included in each intervention contrast in the network on the results of the NMA, including intervention ranking. Study level threshold analysis helps to assess the robustness of the intervention recommendation based on each study individually. Contrast level threshold analysis examines the robustness of the results from the NMA in the combined evidence for each intervention contrast in the network. That is, assuming that direct evidence for the contrast is present in the network, we assess the impact of imprecision in the combined evidence for that particular contrast on the results from the NMA. Contrast level analysis is more useful in guideline development as the robustness of the entire body of evidence is considered, rather than just the individual studies [3]. For the full algebraic breakdown of both study and contrast level threshold analyses, refer to Philippo et al [3].

\section{Application}

We adapted the threshold analysis to allow for the modelling of a random-effects NMA with a binary outcome. We applied it to a published NMA of studies evaluating the effectiveness of several interventions aimed to increase the uptake of poison prevention behaviours in homes with children under 5 [7]. The data were obtained from primary studies identified in two systematic reviews [8]. We replicated the published NMA using a random-effects NMA with a binary outcome; the uptake of poison prevention behaviours within a household. A variety of outcomes were considered in the original NMAs. However, in this paper, we focus on interventions to promote the safe storage of other household products. The data were obtained from 15 studies assessing the effectiveness of 7 different interventions. The studies included 10 RCTs, two NRCTs, two cluster RCTs and one cluster NRCT. As with any NMA, the quality of the studies was assessed before inclusion in the NMA. Table 1 includes the assessment of each study quality as reported [7].

The interventions compared across these studies were:

1. Usual care (UC)

2. Education (E)

3. Education + Free/low cost equipment $(E+F E)$

4. Education + Free/low cost equipment + Fitting $(E+F E+F)$

5. Education + Free/low cost equipment + Home safety inspection $(\mathrm{E}+\mathrm{FE}+\mathrm{HSI})$

6. Education + Free/low cost equipment + Fitting + Home safety inspection $(E+F E+F+H S I)$

7. Free/low cost equipment (FE only) 
Table 1

Results of NMA random-effects model for the safe storage of household products outcome.

\begin{tabular}{|c|c|c|c|c|c|c|c|}
\hline $\begin{array}{l}\text { Odds } \\
\text { Ratio } \\
\text { (95\% } \\
\text { Credible } \\
\text { Interval) }\end{array}$ & $\begin{array}{l}\text { Usual } \\
\text { Care } \\
\text { (UC) }\end{array}$ & $\begin{array}{l}\text { Education } \\
\text { (E) }\end{array}$ & $\begin{array}{l}\text { Education } \\
+ \text { Free/low } \\
\text { cost } \\
\text { equipment } \\
(E+F E)\end{array}$ & $\begin{array}{l}\text { Education } \\
\text { + Free/low } \\
\text { cost } \\
\text { equipment } \\
\text { + Fitting } \\
\text { (E + FE + } \\
\text { F) }\end{array}$ & $\begin{array}{l}\text { Education } \\
+ \text { Free/low } \\
\text { cost } \\
\text { equipment } \\
+ \text { Home } \\
\text { safety } \\
\text { inspection } \\
\text { (E + FE + } \\
\text { HSI) }\end{array}$ & $\begin{array}{l}\text { Education } \\
+ \text { Free/low } \\
\text { cost } \\
\text { equipment } \\
\text { + Fitting + } \\
\text { Home } \\
\text { safety } \\
\text { inspection } \\
\text { (E + FE + F } \\
+ \text { HSI) }\end{array}$ & $\begin{array}{l}\text { Free/low- } \\
\text { cost } \\
\text { equipment } \\
\text { (FE only) }\end{array}$ \\
\hline $\begin{array}{l}\text { Usual } \\
\text { Care (UC) }\end{array}$ & & $\begin{array}{l}1.26 \\
(0.67 \\
2.46)\end{array}$ & $\begin{array}{l}2.24(0.97 \\
5.62)\end{array}$ & $\begin{array}{l}2.514 \\
(0.46 \\
4.31)\end{array}$ & $\begin{array}{l}1.33(0.46 \\
4.31)\end{array}$ & $\begin{array}{l}2.56(0.57 \\
15.15)\end{array}$ & $\begin{array}{l}0.37(0.00 \\
19.63)\end{array}$ \\
\hline $\begin{array}{l}\text { Education } \\
\text { (E) }\end{array}$ & $\begin{array}{l}1.40 \\
(0.81 \\
2.60)\end{array}$ & & $\begin{array}{l}1.78(0.67 \\
4.75)\end{array}$ & $\begin{array}{l}2.00(0.72 \\
6.69)\end{array}$ & $\begin{array}{l}1.06 \\
3.45)\end{array}$ & $\begin{array}{l}2.04(0.40 \\
13.37)\end{array}$ & $\begin{array}{l}0.29(0.00 \\
15.25)\end{array}$ \\
\hline $\begin{array}{l}\text { Education } \\
+ \text { Free/low } \\
\text { cost } \\
\text { equipment } \\
(E+F E)\end{array}$ & $\begin{array}{l}1.99 \\
(0.45 \\
8.04)\end{array}$ & $\begin{array}{l}2.58 \\
(1.12 \\
5.94)\end{array}$ & & $\begin{array}{l}1.122 \\
(0.3438 \\
4.325)\end{array}$ & $\begin{array}{l}0.59(0.15 \\
2.41)\end{array}$ & $\begin{array}{l}1.15(0.20 \\
8.29)\end{array}$ & $\begin{array}{l}0.17(0.00, \\
7.36)\end{array}$ \\
\hline $\begin{array}{l}\text { Education } \\
+ \text { + Free/low } \\
\text { cost } \\
\text { equipment } \\
+ \text { + Fitting } \\
\text { (E + FE + } \\
\text { F) }\end{array}$ & $\begin{array}{l}1.18 \\
(0.96 \\
1.46)\end{array}$ & $\begin{array}{l}1.41 \\
(0.49 \\
4.05)\end{array}$ & NA & & $\begin{array}{l}0.53(0.12, \\
2.07)\end{array}$ & $\begin{array}{l}1.03(0.28 \\
4.21)\end{array}$ & $\begin{array}{l}0.14(0.00, \\
7.94)\end{array}$ \\
\hline $\begin{array}{l}\text { Education } \\
+ \text { + Free/low } \\
\text { cost } \\
\text { equipment } \\
+ \text { + Home } \\
\text { safety } \\
\text { inspection } \\
\text { (E + FE + } \\
\text { HSI) }\end{array}$ & $\begin{array}{l}2 . .98 \\
(0.59 \\
16.94)\end{array}$ & NA & NA & NA & & $\begin{array}{l}1.93(0.28 \\
15.18)\end{array}$ & $\begin{array}{l}0.27(0.00 \\
16.05)\end{array}$ \\
\hline $\begin{array}{l}\text { Education } \\
+ \text { Free/low } \\
\text { cost } \\
\text { equipment } \\
\text { + Fitting + } \\
\text { Home } \\
\text { safety } \\
\text { inspection } \\
\text { (E + FE + F } \\
+ \text { HSI) }\end{array}$ & NA & NA & NA & NA & $\begin{array}{l}1.04(0.81 \\
1.34)\end{array}$ & & $\begin{array}{l}0.14(0.00 \\
9.78)\end{array}$ \\
\hline $\begin{array}{l}\text { Free/low- } \\
\text { cost } \\
\text { equipment } \\
\text { (FE only) }\end{array}$ & NA & NA & $\begin{array}{l}0.32(0.01, \\
7.96)\end{array}$ & NA & NA & NA & \\
\hline
\end{tabular}


The upper triangle contains the results from the NMA, and the lower triangle contains the results from a random-effects pairwise meta-analysis.

The network plot showing the comparisons between interventions evidenced in these studies can be seen in Figure 1.

\section{Results}

Network meta-analysis (NMA)

The results from the NMA can be seen in Table 2, listing the relative effects of all interventions present in the network. The relative effectiveness of the interventions are presented as odds ratios (ORs) with $95 \%$ credible intervals. From Table 2, we can see that most interventions are more effective at increasing the uptake of the poison prevention behaviours for the safe storage of other household items than usual care, apart from the free/low-cost equipment intervention. Using the results of the NMA, we ranked the interventions according to which was the most effective at increasing the uptake of the poison prevention measures in the home. The results from the rankings can be seen in Table 3 . 
Table 2

Details of studies included in NMA for the safe storage of other household products outcome.

\begin{tabular}{|c|c|c|c|c|}
\hline Intervention Comparison & $\begin{array}{l}\text { Study } \\
\text { Number }\end{array}$ & Study & Study quality & $\begin{array}{l}\text { Safe storage of } \\
\text { other } \\
\text { household } \\
\text { products }\end{array}$ \\
\hline Usual care (1) vs. & \multirow[t]{2}{*}{1} & \multirow{2}{*}{$\begin{array}{l}\text { Kelly (1987), RCT, } \\
\text { USA }\end{array}$} & \multirow[t]{2}{*}{$A=U, B=Y, F=N$} & $43 / 54$ \\
\hline \multirow[t]{9}{*}{ Education (2) } & & & & $49 / 55$ \\
\hline & \multirow[t]{2}{*}{2} & \multirow{2}{*}{$\begin{array}{l}\text { Nansel }(2002)^{a} \\
\text { RCT, USA }\end{array}$} & \multirow[t]{2}{*}{$A=Y, B=U, F=Y$} & $65 / 89$ \\
\hline & & & & $66 / 85$ \\
\hline & \multirow[t]{2}{*}{3} & \multirow{2}{*}{$\begin{array}{l}\text { McDonald (2005), } \\
\text { RCT, USA }\end{array}$} & \multirow[t]{2}{*}{$A=Y, B=U, F=N$} & $3 / 57$ \\
\hline & & & & $6 / 61$ \\
\hline & \multirow[t]{2}{*}{4} & \multirow[t]{2}{*}{$\begin{array}{l}\text { Gielen (2007), RCT, } \\
\text { USA }\end{array}$} & \multirow[t]{2}{*}{$A=Y, B=N, F=Y$} & \\
\hline & & & & $57 / 73$ \\
\hline & \multirow[t]{2}{*}{5} & \multirow{2}{*}{$\begin{array}{l}\text { Nansel (2008), } \\
\text { Non-RCT, USA }\end{array}$} & \multirow[t]{2}{*}{$\mathrm{A}=\mathrm{U}, \mathrm{B}=\mathrm{N}, \mathrm{F}=\mathrm{N}$} & $59 / 73$ \\
\hline & & & & $117 / 144$ \\
\hline \multirow{4}{*}{$\begin{array}{l}\text { Usual care (1) vs Education + } \\
\text { Free/low cost Equipment ( } 3 \text { ) }\end{array}$} & \multirow[t]{2}{*}{6} & \multirow{2}{*}{$\begin{array}{l}\text { Woolf (1992), } \\
\text { Cluster-RCT, USA }\end{array}$} & \multirow[t]{2}{*}{$A=U, B=Y, F=N$} & $60 / 151$ \\
\hline & & & & $89 / 150$ \\
\hline & \multirow[t]{2}{*}{7} & \multirow{2}{*}{$\begin{array}{l}\text { Clamp (1998), RCT, } \\
\text { UK }\end{array}$} & \multirow[t]{2}{*}{$\mathrm{A}=\mathrm{U}, \mathrm{B}=\mathrm{N}, \mathrm{F}=\mathrm{Y}$} & $49 / 82$ \\
\hline & & & & $59 / 83$ \\
\hline Usual care (1) vs. & \multirow[t]{2}{*}{8} & \multirow{2}{*}{$\begin{array}{l}\text { Kendrick (1999), } \\
\text { Cluster non-RCT, } \\
\text { UK }\end{array}$} & \multirow[t]{2}{*}{$B=N, F=N, C=Y$} & $317 / 367$ \\
\hline \multirow{5}{*}{$\begin{array}{l}\text { Education + Equipment + Home } \\
\text { Safety inspection (4) }\end{array}$} & & & & $322 / 363$ \\
\hline & \multirow[t]{2}{*}{9} & \multirow[t]{2}{*}{$\begin{array}{l}\text { Swart (2008), Non- } \\
\text { RCT, South Africa }\end{array}$} & \multirow[t]{2}{*}{$A=U, B=Y, F=Y$} & $46.86 / 57.96^{b}$ \\
\hline & & & & $50.87 / 58.27^{b}$ \\
\hline & \multirow[t]{2}{*}{10} & \multirow{2}{*}{$\begin{array}{l}\text { Hendrickson } \\
\text { (2002), USA, RCT }\end{array}$} & \multirow[t]{2}{*}{$A=N, B=N, F=Y$} & $14 / 40$ \\
\hline & & & & $34 / 38$ \\
\hline Usual care (1) vs. & 11 & Watson (2005), & $A=Y, B=N, F=Y$ & $327 / 669$ \\
\hline Education + Equipment (5) & & & & $368 / 693$ \\
\hline Education (2) vs. & 12 & Posner (2004), RCT, & $A=Y, B=Y, F=N$ & $22 / 47$ \\
\hline Education + Equipment (3) & & & & $34 / 49$ \\
\hline Education (2) vs. & 13 & $\begin{array}{l}\text { Sznajder (2003), } \\
\text { RCT, France }\end{array}$ & $A=Y, B=N, F=Y$ & $32 / 41$ \\
\hline Education + Equipment (5) & & & & $40 / 48$ \\
\hline
\end{tabular}




\begin{tabular}{|lllll|}
\hline Intervention Comparison & $\begin{array}{l}\text { Study } \\
\text { Number }\end{array}$ & Study & Study quality & $\begin{array}{l}\text { Safe storage of } \\
\text { other } \\
\text { household } \\
\text { products }\end{array}$ \\
\hline $\begin{array}{l}\text { Education+ equipment (3) vs. } \\
\text { Equipment only (7) }\end{array}$ & 14 & $\begin{array}{l}\text { Dershewitz (1977), } \\
\text { RCT, USA, }\end{array}$ & $\mathrm{A}=\mathrm{U}, \mathrm{B}=\mathrm{Y}, \mathrm{F}=\mathrm{N}$ & $1 / 101^{\mathrm{c}}$ \\
\hline $\begin{array}{l}\text { Education + Equipment + home } \\
\text { Safety inspection (4) vs. }\end{array}$ & 15 & $\begin{array}{l}\text { King (2001), RCT, } \\
\text { USA } \\
\begin{array}{l}\text { Education + equipment + home } \\
\text { safety inspection + Fitting (6) }\end{array}\end{array}$ & $\mathrm{A}=\mathrm{Y}, \mathrm{B}=\mathrm{Y}, \mathrm{F}=\mathrm{Y}$ & $0 / 104^{\mathrm{c}}$ \\
\hline
\end{tabular}

Last column includes the number of households with safe storage out of the total number of storage. Abbreviations:

- $A=$ adequate allocation concealment; $B=$ blinded outcome assessment; $C$, the prevalence of confounders does not differ by more than $10 \%$ between treatment arms; CBA, controlled before-andafter study; $F$ = at least $80 \%$ participants followed up in each arm; NMA, network meta-analysis; RCT, randomised clinical trial; $U=$ unclear, $Y=$ yes.

- a Two intervention arms were combined (tailored advice and tailored advice + care provider feedback)

- ${ }^{b}$ Figures adjusted for the effect of clustering using ICC and method reported Kendrick et al. (2012)

- Continuity correction applied by adding 0.5 and 1 to denominator and numerator to account for the zero events reported (no households that were assessed safely stored other household products). 
Table 3

Table of the ranking of intervention for the safe storage of other household products outcome

\begin{tabular}{|llll|}
\hline Intervention & $\begin{array}{l}\text { Ranking }(95 \% \\
\text { Credible Interval) }\end{array}$ & $\begin{array}{l}\text { Probability } \\
\text { intervention is the best }\end{array}$ \\
\hline $\mathbf{1}$ & Usual care (UC) & $6(4,7)$ & 0.00 \\
\hline $\mathbf{3}$ & $\begin{array}{l}\text { Education (E) } \\
\text { (E + FE) }\end{array}$ & $5(2,7)$ & 0.01 \\
\hline $\mathbf{4}$ & $\begin{array}{l}\text { Education + Free/low cost Equipment } \\
\text { (E + FE + F) }\end{array}$ & 0.22 \\
\hline $\mathbf{5}$ & $\begin{array}{l}\text { Education + Free/low cost Equipment + Home } \\
\text { safety inspection } \\
\text { (E + FE + HSI) }\end{array}$ & $2(1,6)$ & 0.22 \\
\hline $\mathbf{6}$ & $\begin{array}{l}\text { Education + Free/low cost Equipment + Fitting + } \\
\text { Home safety inspection } \\
\text { (E + FE + F + HSI) }\end{array}$ & $2(1,7)$ & 0.05 \\
\hline 7 & $\begin{array}{l}\text { Free/low-cost equipment only } \\
\text { (FE only) }\end{array}$ & 0.37 \\
\hline
\end{tabular}

From Table 3, we can see that the intervention with the highest probability of being the most effective is education + free/low-cost equipment + fitting + home safety inspection $(E+F E+F+H S I)$, which is the most intensive intervention. This intervention was also ranked highest along with education + free/low-cost equipment + fitting $(E+F E+F)$. The least effective interventions were usual care and free/low-cost equipment only. There was overlap between the $95 \%$ credible intervals for the rankings for all the interventions, indicating that no distinct intervention is optimal or worst.

Study level threshold analysis

The studies are sorted according to those with the smallest thresholds, with the intervention contrasts for each particular study identified in the brackets; the studies emphasised in bold represent those in which the $95 \%$ confidence interval for the effect estimate extends beyond the invariant interval. Where the $95 \% \mathrm{Cl}$ extends beyond the invariant interval, the invariant interval is coloured red rather than light blue. The optimal intervention for this NMA is intervention 6. The new optimal intervention is displayed for that particular study on either side of the invariant intervals. NT indicates "No threshold", meaning that no threshold exists in that particular direction, so no amount of adjustment in that particular direction would change the optimal intervention from intervention 6 .

Figure 2 presents the results of the study level threshold analysis. We can see that of the 15 studies included in the network meta-analysis, 7 studies had $95 \%$ confidence intervals extending beyond the invariant interval (indicated in bold). This demonstrates that the intervention recommendations are sensitive to the amount of 
imprecision in the study estimates in studies: $6,7,9,10,12,14$, and 15. For example, for study 15, which compared interventions 4 and 6, the estimated log OR of 0.04 had an invariant interval of $(0.00, N T)$. This indicates that a change of -0.04 in the log OR would change the optimal intervention recommendation from intervention 6 to intervention 4. The NT in the upper invariant interval represents "No threshold", which illustrates that no amount of change in this direction would change the optimal intervention recommendation. For study 10, which compared interventions 1 and 4, the estimated log OR of 2.76 has an invariant interval of $(2.19,50.88)$. This illustrates that a change in the log OR of -0.57 is substantial enough to change the intervention recommendation from intervention 7 to intervention 3 . Therefore, a change in the log odds ratio of 0.82 would change the intervention recommendation to intervention 3 being the most optimal rather than intervention 6 . However, for studies 6 and 12, the upper limits of the invariant intervals lie very close to the upper limits of the $95 \%$ confidence intervals. For the remaining 8 studies, their relative $95 \%$ confidence intervals fall within the invariant intervals, which indicates that no amount of change in the study estimates would change the intervention recommendation as the bias adjustment threshold is very large.

Contrast level threshold analysis

Figure 3 shows the results from the contrast level threshold analysis. Five of the intervention contrasts in the network have either upper or lower portions of their respective invariant intervals outside of the $95 \%$ credible intervals, indicating that the decision for these contrasts are sensitive to the level of imprecision in these estimates. For the other two contrasts in the network (2 vs 1, 5 vs 2), the invariant intervals are wide and contain the $95 \%$ credible interval for each estimate. This indicates that the average effectiveness estimates for these comparisons are robust to any changes in the evidence. The results from Figure 3 are consistent with those depicted in the study level threshold analysis (Figure 2).

It is important to note that when only one study observes a particular contrast in the network, the results of the threshold analyses at study level and contrast level must be consistent. From Figure 1, there are two twoarm studies in the network, which are single studies for comparisons 7 vs 3 and 6 vs 4 . From Figure 3, we can see that the thresholds for the contrast 6 vs 4 are identical to those corresponding to study 15 in the study level analysis (as seen in Figure 2), as expected. However, we can see that the $95 \%$ credible interval for the effect estimate is wider in the contrast level analysis than the $95 \%$ confidence interval in the study level analysis. This is due to the combined NMA result being less precise than the study estimate due to the large level of heterogeneity in the NMA. However, for the 7 vs 3 contrast, both the effect estimates and thresholds are different at the study level and the contrast level. Despite the quantitative differences between the study level and the contrast level analyses for this comparison, the results for this particular contrast/study are consistent qualitatively. There is a lot of uncertainty around the effect estimate for this contrast/study, and the upper threshold (in favour of intervention 7) lies well within the confidence interval at study level and credible interval at contrast level.

\section{Discussion}


The network meta-analysis identified that the most intensive intervention is the most effective at increasing the uptake of the poison prevention behaviours for the safe storage of other household products to promote poison prevention behaviours in homes with children under 5 . The usual care and free/low-cost equipment interventions were identified as the least effective interventions. The results from the NMA and both the study and contrast level threshold analyses indicated that no distinct intervention could be recommended as the most optimal intervention. This is illustrated by the credible intervals for the effect estimates from the NMA and the overlapping intervention rankings. In the threshold analysis, this was reflected in the small thresholds identified in the analyses, which meant that a small change in the evidence would result in an alternative intervention being most effective. Furthermore, the intervention recommendation from the NMA was not robust, as the effectiveness estimate was sensitive to the level of imprecision in the evidence and potential bias.

As recommended by Phillippo et al [3], any studies with reasonably small thresholds need to be assessed for risk of bias by using the tools discussed previously. From the threshold analysis, there were 3 studies with thresholds less than 0.5 ; these were studies 6,7 and 15 . By referring to the study quality assessment in Table 2, these studies did not appear to be particularly at risk of bias and did not have any major issues with their quality.

A limitation of this work is that threshold analysis has only been applied to one example of a public health intervention evidence synthesis. A further limitation is that the published NMA example only had a small number of studies. There was little evidence for many of the contrasts. As well as this, there was no distinct or clear intervention recommendation from the NMA as all effect estimates contained 1 , and the rankings overlapped. However, this example still illustrates the use of NMA and threshold analysis in the context of public health.

Threshold analysis allows researchers to identify and quantify the robustness of intervention recommendations from NMAs to any potential bias in the evidence. The use of this method provides researchers and policy makers with the confidence that their results from NMAs are robust to changes in the evidence that might be due to bias. It is important to note that threshold analysis does not investigate the presence or absence of any particular bias and does not make any assumptions on the type and source of the bias. Threshold analysis is more concerned with the implications, if there is any bias present, that such bias would have on the intervention recommendations and resulting decisions.

There still should be some careful consideration when applying complex evidence synthesis methods to highly heterogeneous data, as this method is not a way to fix the issues that arise. The primary consideration with heterogeneity is that we should account for it appropriately rather than avoid complex analyses due to the arising issues. Heterogeneity is inevitable, especially in public health intervention appraisals. The use of advanced methods for evidence synthesis, including the appropriate account of the heterogeneity, can lead to more detailed and robust conclusions, which will improve research and aid the decision-making process.

Threshold analysis could be extended to incorporate GRADE judgements in the analyses, as seen in the paper by Holper 2019 [9]. The use of GRADE judgements alongside threshold analysis offers a qualitative 
judgement as well as quantitative. Threshold analysis could also be incorporated into a cost-effectiveness analysis to consider the robustness of decisions on the cost-effectiveness of interventions.

A further application of threshold analysis could be to components network meta-analysis. Component network meta-analysis expands on the NMA framework and splits the interventions into components to consider which combination of components is most effective. The interventions in the NMA assessed in this example consist of several components, for example, education, fitting, and home safety inspection, so it could be more appropriate to explore which combinations of these components, not just the ones observed, are most effective. As well as this, in recent literature, threshold analysis has been applied to continuous and binary outcomes. These methods could be extended to look at other possible outcomes.

\section{Conclusion}

Applying threshold analysis to a NMA of public health interventions, we have highlighted that the intervention recommendation for the network was not robust, as the decision was sensitive to the imprecision in the effect estimate and to possible bias. We have illustrated that threshold analysis gives an insight into the effects of changes in the evidence on the resulting intervention decisions. The application of threshold analysis should ease any hesitancy to use complex evidence synthesis methods, such as NMA, in public health intervention appraisals. The increase in the use of such methods in public health intervention appraisals can improve the standard of the evaluation of interventions and, consequently, the decisionmaking process, with benefit to policy-makers and the public.

\section{Abbreviations}

NICE: National institute for health and care excellence

NMA: Network meta-analysis

RCT: Randomised controlled trial

NRCT: Non-randomised controlled trial

GRADE: Grading of Recommendations Assessment, Development and Evaluation

UC: Usual care

E: Education

FE: Free/low cost equipment

F: Fitting

HSI: Home safety inspection

OR: Odds ratio 
Crl: Credible interval

Cl: Confidence interval

\section{Declarations}

\section{Ethics approval and consent to participate}

Not applicable.

\section{Consent for publication}

Not applicable.

\section{Availability of data and materials}

The dataset supporting the conclusions of this article is included within the article.

\section{Competing interests}

The authors declare that they have no competing interests.

\section{Funding}

This research was funded by a National Institute for Health Research (NIHR) Pre-doctoral Fellowship awarded to MW [NIHR300453]. The views expressed are those of the author(s) and not necessarily those of the NIHR or the Department of Health and Social Care. The funding bodies played no role in the design of the study and collection, analysis, and interpretation of data and in writing the manuscript.

SB was funded by Medical Research Council [grant no. MR/R025223/1].

This project was supported by the National Institute for Health Research (NIHR) Applied Research Collaboration East Midlands (ARC EM). The views expressed are those of the author(s) and not necessarily those of the NIHR or the Department of Health and Social Care.

\section{Authors' contributions}

MW conducted the NMA and threshold analysis, analysed the results and wrote the paper. SH and SB supervised the project. All authors have read and approved the manuscript.

\section{Acknowledgements}

The authors thank David Phillippo for technical advice on the application of his software for the use of threshold analysis.

\section{Authors' information}




\section{References}

1. Dias, S., Ades, A. E., Welton, NJ., Jansen, JP., Sutton, AJ., 2018. Network Meta-Analysis for Decision Making. [online] First ed. Chichester: John Wiley And Sons [cited 2021 Jun 25] Available from: https://onlinelibrary.wiley.com/doi/book/10.1002/9781118951651.

2. Smith EA, Cooper NJ, Sutton AJ, Abrams KR, Hubbard SJ. A review of the quantitative effectiveness evidence synthesis methods used in public health intervention guidelines. BMC public health. 2021 Dec;21(1):1-25.

3. Phillippo DM, Dias S, Ades AE, Didelez V, Welton NJ. Sensitivity of treatment recommendations to bias in network meta-analysis. Journal of the Royal Statistical Society. Series A,(Statistics in Society). 2018 Jun;181(3):843.

4. Jørgensen L, Paludan-Müller AS, Laursen DR, Savović J, Boutron I, Sterne JA, Higgins JP, Hróbjartsson A. Evaluation of the Cochrane tool for assessing risk of bias in randomised clinical trials: overview of published comments and analysis of user practice in Cochrane and non-Cochrane reviews. Systematic reviews. 2016 Dec;5(1):1-3.

5. Phillippo DM, Dias S, Welton NJ, Caldwell DM, Taske N, Ades AE. Threshold analysis as an alternative to GRADE for assessing confidence in guideline recommendations based on network meta-analyses. Annals of internal medicine. 2019 Apr 16;170(8):538-46.

6. Dias, S., Welton, N.J., Sutton, A.J., Ades, A.E. NICE DSU Technical Support Document 1: Introduction to evidence synthesis for decision making. 2011; last updated April 2012; available fro

7. Achana FA, Sutton AJ, Kendrick D, Wynn P, Young B, Jones DR, Hubbard SJ, Cooper NJ. The effectiveness of different interventions to promote poison prevention behaviours in households with children: a network meta-analysis. PLoS one. 2015 Apr 20;10(4):e0121122.

8. Wynn PM, Zou K, Young B, Majsak-Newman G, Hawkins A, Kay B, Mhizha-Murira J, Kendrick D. Prevention of childhood poisoning in the home: overview of systematic reviews and a systematic review of primary studies. International journal of injury control and safety promotion. $2016 \mathrm{Jan}$ 2;23(1):3-28.

9. Holper L. Combining threshold analysis and GRADE to assess sensitivity to bias in antidepressant treatment recommendations adjusted for depression severity. Research synthesis methods. 2020 Mar;11(2):275-86.

\section{Figures}




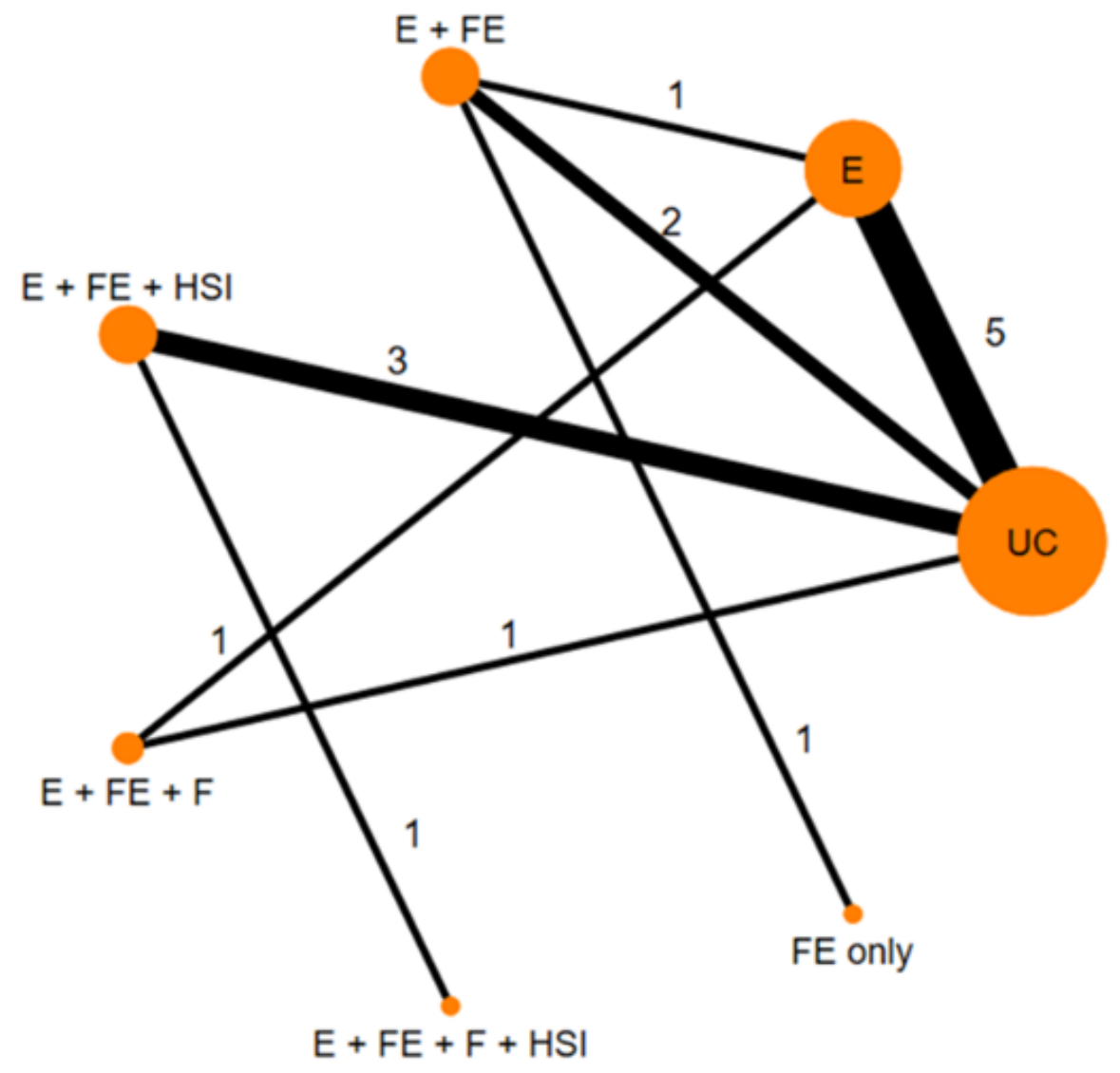

Circles/Nodes represent an intervention (UC $=U$ usual care, $E=$ Education, $F=$ Fitting, $F E=$ Free $/$ Low cost equipment, HSI = Home Safety Inspection). The lines between any two nodes represent a pairwise contrast/comparison connecting the nodes. The numbers on the lines, and thickness of the lines, correspond to the total number of studies contributing to that particular contrast.

Figure 1

Network of interventions to prevent poisonings in the home of children aged 0-5 


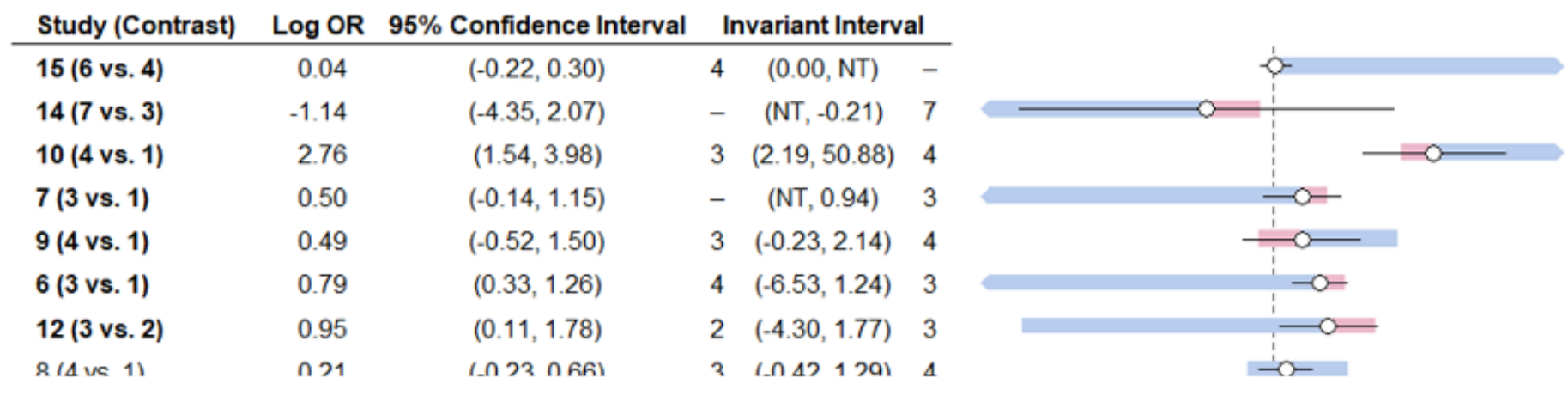

Figure 2

Study level forest plot for the safe storage of other household products outcome.

Figure 3

Contrast level threshold analysis for safe storage of other household products outcome. 